\title{
La poderosa diosa Maât ${ }^{1}$
}

\section{The mighty goddess Maât}

\author{
JOSÉ CARLOS CASTAÑEDA REYES \\ Universidad Autónoma Metropolitana-Iztapalapa, México
}

Resumen: En este artículo se estudian las características fundamentales de la diosa Maât y su papel clave para mantener el equilibrio y el orden del cosmos. Se parte del examen de la "Maât de Florencia" por su perfección plástica y se presentan diversas facetas de la diosa, no tanto como idea abstracta ético-moral sino en un intento de resaltar su significado en el pensamiento egipcio, sus particularidades como divinidad en el panteón y sus relaciones con otros númenes. A continuación se analiza su presencia en la literatura egipcia como reflejo de esta sociedad, y, finalmente, su carácter femenino como símbolo de las mujeres egipcias. Se insiste en que su naturaleza femenina es la base de su posición central en la cosmovisión del Egipto antiguo, y encarna la importancia de la mujer en esa civilización antigua, que se puede considerar más uterina que fálica, a decir de los autores consultados.

Recepción: 20 de agosto de 2018. / Aceptación: 27 de mayo de 2019.

${ }^{1}$ El autor expresa su gratitud a la Oriental Institute Library y a la Regenstein Library de la Universidad de Chicago; a la Chicago House Library en Luxor, Egipto; a la biblioteca del Institute français d'archéologie orientale, El Cairo; a la biblioteca del American Research Center in Egypt; a la Butler Library, Columbia University, Nueva York; al Institute for the Study of the Ancient World Library, New York University, EE.UU., por su amable hospitalidad durante el proceso de investigación de este artículo. 
Palabras clave: orden cósmico; diosa Maât; civilización uterina; Florencia; mujeres egipcias.

Abstract: In this article we study the fundamental characteristics of the goddess Maât, highlighting her instrumental role in maintaining the balance and order of the cosmos. We start by studying the "Maât de Firenze", considering her plastic perfection, before presenting different facets of the goddess. Instead of understanding her as an ethical-moral abstract construct, we highlight her importance for Egyptian thought, her characteristics as a divinity in the pantheon and her relation with other gods. Then we analyze her role in Egyptian literature and finally her female character as a symbol of Egyptian women. The central argument is that her feminine nature forms the basis of her central position in the worldview of ancient Egypt. She embodies the importance of women in this ancient civilization, defined by some authors as uterine more than phallic.

Keywords: cosmic order; goddess Maât; uterine civilization; Florence; Egyptian women.

\section{Introducción: la "Maât de Florencia"}

Sin duda, una de las imágenes femeninas más gráciles y hermosas del arte egipcio es el famoso relieve del Museo Arqueológico Nacional de Florencia que representa a la diosa, $M 3 \_t,{ }^{2}$ Maât, la joven deidad hija de Râ (figura 1). Su belleza supera a la de la Dama Thepu, que algunos consideran "la más hermosa dama egipcia”. Thepu fue la madre de Nebamón, superintendente de escultores y administrador de los talleres reales. Comparte su tumba (TT181) con Apuki (dinastía XVIII, época de Amenhotep III) (Davies, 1925, pp. 9-12, 16, genealogía) (figura 2).

${ }^{2}$ Sobre la etimología del nombre, $c f r$. Stern, 1878a, pp. 72-78, y Vergote, 1961, pp. 69-78. Las representaciones plásticas de la diosa se conocen al menos desde mediados del Reino Antiguo, procedentes de theophoric names, a decir de Teeter (2001, pp. 319-320). 


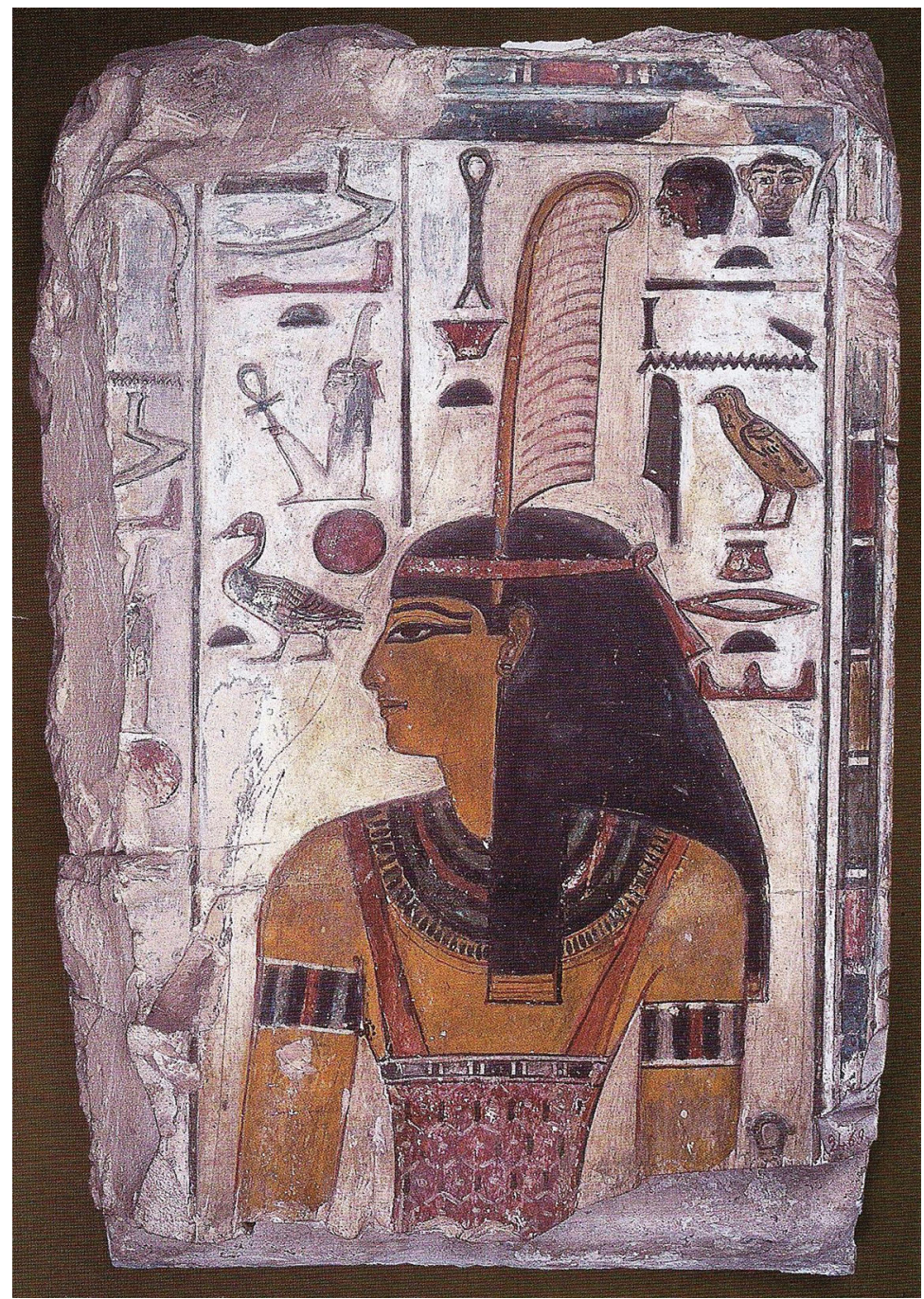

Figura 1. La diosa Maât de Florencia

(Firenze. Museo Archeologico Nazionale, Polo Museale della Toscana, número de catálogo 2469. Se reproduce con la amable autorización del Polo Museale). 


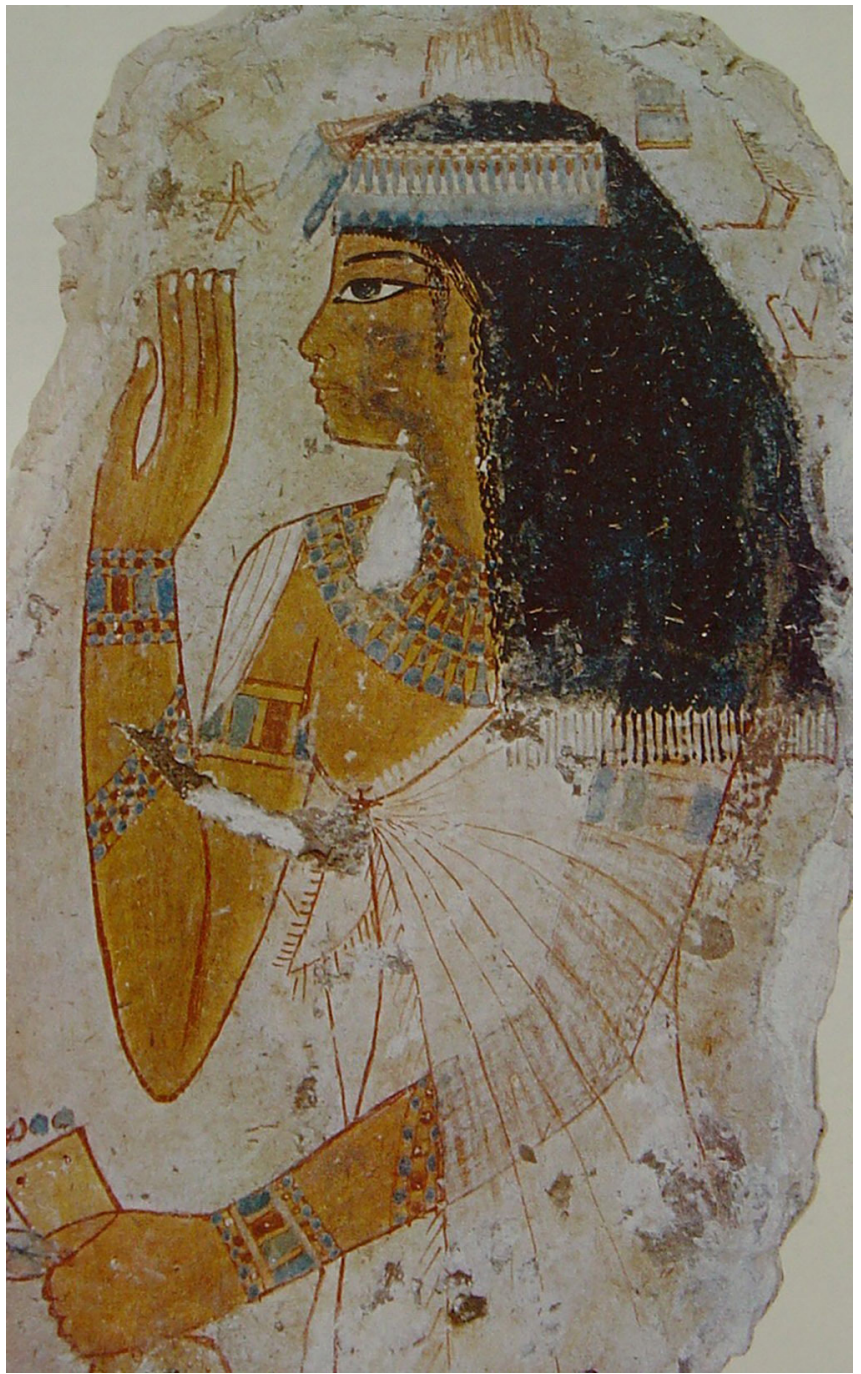

Figura 2. La dama egipcia Thepu.

(Pintura de la época de Amenhotep III, dinastía XVIII. De la tumba de su hijo, el escultor Nebamón [TT181]. Brooklyn Museum núm. 65.197. Charles Edwin Wilbour Fund. Se reproduce con la amable autorización del museo). 
El relieve de la diosa procede de la tumba de Seti I (dinastía XIX) ${ }^{3}$ y lleva el número de entrada al museo $2469 .{ }^{4} \mathrm{El}$ autor del catálogo es muy escueto. Menciona su hallazgo en la tumba de Seti I por Belzoni. Durante la expedición franco-toscana ${ }^{5}$ fue "transportada" a Italia. Representa a la diosa "Tme, justice et verité, mentionée souvent, sur ces mémoires funèbres" (Migliarini, 1859 , p. 26). Vale la pena recuperar la descripción de la pieza por parte de Rosellini (1830, p. 49):

Núm. 50. Bello bajorrelieve pintado en piedra caliza. Representa a la diosa que, bajo la doble y promiscua denominación de Justicia y Verdad, presidía el Amenti, el tribunal tremendo de la otra vida. Se lee en torno Tme (Verdad y Justicia) Diosa bija del sol, rectora y centro del mundo, residente en la tierra de Kel (el Amenti).

Por su parte, Ernesto Schiaparelli (1887, p. 322) considera que la pieza es parte de un bajorrelieve incompleto. ${ }^{6}$ Describe así la figura de la diosa:

lleva un vestido estrecho, pegado a su cuerpo, sostenido por dos correas. En el pecho luce un gran collar, y el pelo aparece cubierto con un velo

${ }^{3}$ Sobre la tumba de este notable faraón, $c f r$. Weigall, 1910, pp. 213-216.

${ }^{4}$ La imagen ha sido utilizada por diversos egiptólogos para ilustrar sus obras sobre el tema. Hasta donde sé, no ha sido objeto de un estudio monográfico específico. Sobre las diversas representaciones de la diosa, $c f r$. Künh, 2012, pp. 25-29.

${ }^{5}$ La famosa "Spedizione Letteraria Toscana in Egitto" fue dirigida por Ippolito Rosellini (Pisa, 1800-1843) entre el 21 de julio de 1828 y el 18 de agosto de 1829. El fundador de la egiptología italiana acariciaba la idea de viajar a Egipto, al igual que el mismo Jean-Françoise Champollion, y a pesar de la opinión del hermano del segundo: "Buscar piedras en Egipto es asunto de los Caillaud y otras personas con buenas piernas y buen estómago", ambos personajes lograron su objetivo con apoyo del Granduca di Toscana, Leopoldo II. En 15 meses recorrieron Egipto y Nubia hasta el Wadi Halfa. Del recorrido recopilaron una masa de notas, copias de textos jeroglíficos, diseños (1325 según Roselllin), la base del desarrollo de la egiptología. Gracias al viaje, Champollion completó su Grammaire... (Betró, 2010, pp. 4, 10, 22). Y la diosa Maât llegó a Florencia, entre las casi 2000 piezas que los expedicionarios llevaron tan sólo a Italia (Guidotti, 2010, p. 46).

${ }^{6}$ El relieve tiene de alto $76 \mathrm{~cm}$ y de largo, 47. 
negro anudado detrás de su nuca. A la altura de la oreja izquierda resalta su característica pluma de avestruz que la distingue. ${ }^{7}$

La pluma de Maât implicaría, precisamente, su relación con las divinidades aéreas, ${ }^{8}$ al igual que significa "luz" por su relación filial con la divinidad solar. Por ello se liga con una arquitectura que tiene que ver con el culto al Sol, en su papel de Señora de la Luz Solar (Westendorf, 1971, pp. 143-146). La piel de la diosa es amarillo claro, según la típica convención egipcia, en este caso además con esta implicación simbólica particular: el color de la luz.

Berend (1882, pp. 2-3), por su parte, presenta la inscripción que acompaña el relieve que identifica a la diosa como hija de Râ y protectora de la tierra de Iugrt, la "necrópolis de Heliópolis”, la antigua Iunu u On.

La belleza y la perfección plástica de la diosa Maât de Florencia constituyen la presentación de este trabajo, en el que se intenta resaltar el significado de este numen en el pensamiento egipcio, sus características como divinidad en el panteón y sus relaciones con otros dioses, para luego analizar su presencia en la literatura egipcia como reflejo de esa sociedad. A partir de esta necesaria revisión, se insiste en que su naturaleza femenina es el fundamento de su posición central en la cosmovisión del Egipto antiguo, y encarna simbólicamente la importancia de la mujer en esa civilización antigua, que se puede considerar, tal vez, más uterina que fálica, a decir de los autores que se citan en su oportunidad y según nuestra propia perspectiva al respecto.

${ }^{7}$ Si bien lo más común es que el numen sea representado con una sola pluma de avestruz, también puede aparecer con dos o más, según ejemplos del Imperio Nuevo y del Tercer Periodo Intermedio, a decir de Teeter (1985-1986, pp. 43-52). Cita como ejemplos de lo anterior la tumba de Nakhtamun en Tebas (TT335) y diversos papiros funerarios de las dinastías XIX a XXI (papiros de Taujare, Khonsumes B, y Chaymenu, entre otros ejemplos). La autora señala que esta variación es producto de "las innovaciones iconográficas del periodo Amarna" (Teeter, 1985-1986, p. 47).

${ }^{8}$ Así opina también Stern (1877a, p. 78), que la llama "Herrin der Winde" [Amante de los Vientos]. 


\section{Maât y su significado en el pensamiento egipcio}

Para M. Bilolo (1988, p. 7), en el concepto de maât confluyen cuatro ideales: el ideal del conocimiento (tmbi r r $b$ ), o sea, el amor por el saber, por aquello que es verdadero, seguro, cierto; el ideal moral de la verdad, de la justicia, de la rectitud $(m 3 \varepsilon t)$; el ideal metafísico del amor por el conocimiento del ser ( $b p r)$, y, finalmente, el ideal "ecológico", de respeto al orden cósmico y a la naturaleza, con un compromiso por el devenir ( $h p r)$ o el destino $(s 3 i)$ de la humanidad. Tales principios concurren en la idea fundamental que expresa la inscripción autobiográfica de la tumba de Rekhmire (TT100), sacerdote de Maât antes de ser visir ${ }^{9}$ del faraón ${ }^{10}$ en Tebas, el ideal derivado de la educación y de la vida al servicio de la diosa de la Justicia (Newberry, 1900, p. 19), ${ }^{11}$ que está por encima del mismo monarca que debe guardarla. Por lo tanto, el iri maât, "hacer la maât", sirve

Para elevar la verdad a las Alturas de los cielos, y circular sus bellezas sobre el ancho de las tierras. Yo juzgué al débil con la fuerza, yo protegí a aquellos que eran débiles, y castigué a los malvados y violentos [...] Yo animé al que estaba triste y sin esperanza, apoyé a la viuda sin un marido. Y establecí al hijo en la heredad de su padre (Théodoridès, 1995, p. 19). ${ }^{12}$

${ }^{9}$ Sabido es que el término visir es una "traducción convencional del término que designa al ministro principal o cabeza de la administración” (Serrano, 1998, p. 357). Su uso es realmente discutible por su relación con la historia del islam. De ahí la forma "primer ministro", que me parece más correcta, y que creo que puede aplicarse. Empero, retomo en estas páginas la forma convencional de visir, utilizada comúnmente en egiptología.

${ }^{10}$ Newberry (1900, p. 14) señala que los visires o primeros ministros, al parecer, siempre eran escogidos entre los sacerdotes de la diosa.

${ }^{11}$ Como explica Théodoridès (1995, pp. 15-16), la aplicación de la maât no era privativa del faraón: cualquier funcionario, y sobre todo el $t 3 t y$, debía iri mâat, “ejercer la justicia [...] Ésta es la forma correcta de conducta legal iluminada por el significado de mât'”.

${ }^{12}$ Gardiner (1925, pp. 69-70) tradujo: "I exalted Justice to the height of heaven, I caused her beauty to circulate over the breadth of earth, so that she might rest in (men's) nostrils like the northwind when it has banished what was malignant in heart and body. I judged po[or and] rich (alike). I rescued the weak from the strong. I repelled the fury of the ill-disposed, and quelled him who was covetous in his hour (of covetousness). I [checked] the impulse of him who was infuriated. I restrained 
Con ello se ve que el iri maât implica no sólo un pensamiento racional, sino también un movimiento emotivo, nutrido desde dentro del individuo, alimentado por el $i b$, el corazón de la persona que lo practica (Théodoridès, 1995, p. 16). Por tanto, "hacer la maât" debe entenderse como "ejercer la justicia”, por parte tanto del faraón como de los funcionarios delegados por él para tal ejercicio (Théodoridès, 1995, p. 15).

La tendencia a estudiar la maât desde el punto de vista éticomoral está plenamente desarrollada en las obras de Assmann (1990), Hornung (1989, pp. 385-427) y Karenga (1994), ${ }^{13}$ pero no las retomo aquí.

De hecho, la diosa es un ejemplo de la divinización de abstracciones entre los egipcios, cuyo pensamiento es concreto, no abstracto. ${ }^{14}$ Ello quiere decir, como bien explica Derchain (1965, p. 13), que "la abstracción no existe todavía en el espíritu del egipcio; el orden no lo concibe como una serie de relaciones obligatorias, sino como una fuerza concreta que impone estas relaciones". Independientemente de ello, tanto la diosa Maât como la diosa Atenea de Saïs, identificada con Isis en este famoso templo, bien hubieran podido exclamar: "Yo soy todo lo que ha sido, es y será, y ningún mortal jamás ha levantado mi peplo" (Plutarco, 1987, p. 9), que Wiedemann (1887, p. 564) interpreta como "y mi misterio no ha sido revelado por ningún mortal".

En su nombre, el signo Aa11 remite al espacio húmedo y fertilizante, es decir el agua y la tierra, a la que se agrega el in-

weeping by substituting a comforter (?) I defended the widow who had no husband. I established the son and heir on the seat of his father. I gave [bread to the hungry] and water to the thirsty, meat, oil and clothing to him who had none. I revived (?) the old man, giving [to him] my stick. I caused the old women to say: 'what (?) a happy occasion!". Cfr. traducción y comentarios de Hermann (1940, p. 132). Este autor remite al Urk.Iv (1077, 13-1078, 3) para la transcripción del texto. Su traducción dice: "Ich erhob die Wahreit bis zur Höhe des Himmels, ich verbreitete ihre Schönheit soweit die Erde reicht”, lo cual sería la idea fundamental de la obra de Maât.

${ }^{13}$ Este autor intenta establecer las bases para un estudio "ético filosófico" del concepto y su "contribución potencial al discurso social moderno" (p. 751).

${ }^{14} \mathrm{Cfr}$. respecto de la consideración del numen desde este punto de vista, el estudio clásico de Wiedemann (1887, pp. 559-573). 
flujo benéfico del aire o la atmósfera, simbolizado por su pluma (Shirun-Grumach, 1985, pp. 180-181). Con ello, Maât sería el símbolo perfecto de la fertilidad en el País de las Dos Tierras, responsable de la inundación del Nilo mismo (Teeter, 2001, p. 319). Pero también el signo, enhiesto, puede identificarse con la colina que simboliza el ascenso de la vegetación desde la tierra. Así, su analogía con la "colina primordial" y el trono del faraón parece clara. De ahí puede derivarse la idea que defiende Brunner (1958, pp. 426-428) de la correlación de la colina primordial desde la que fue creado el mundo y que queda simbolizada en el trono real, desde donde el faraón gobierna a aquél a través de la justicia, la maât. La diosa constituye la principal y potente fuerza legitimadora ${ }^{15}$ de su mando sobre Egipto (Teeter, 1997, p. 82). Por eso también su posible analogía con el trono real, según opina Shirun-Grumach (1985, pp. 173-174), siguiendo a Bleeker (1929). Para ellos, los signos Aa11 y EG N37 simbolizarían tal correspondencia, en el segundo caso con lo que sería un "pedazo medido de tierra". El orden sería, entonces, "estar en concordancia con una medida inamovible".

En el campo del derecho, maât simboliza la noción ideal de aquél, es decir la verdad y la justicia, que reposan sobre la distinción fundamental: maât como opuesta a la isft, "lo equivocado", al grg, "la falsedad" (Lichtheim, 1992, p. 18), ${ }^{16}$ o sea, el desorden, la iniquidad, la mentira, como derecho universal o natural que luego se encontrará en los escritos platónicos. Thot, por su parte, "el corazón del dios Sol", ${ }^{17}$ es el juez que aplica el derecho derivado de maât, es el $s r n m 3 s . t$, el "magistrado de maât", y el modelo del faraón, primero, y del visir

${ }^{15}$ Legitimación que descansa en tres aspectos: el religioso, el político y el jurídico, que interjuegan en la ideología real asociada al faraón. Vid. Gundlach, 1997, passim, y diagrama de p. 20).

${ }^{16}$ Los términos que los egipcios utilizan como opuestos a la maât son diversos. Vid. el recuento y el análisis de éstos que realiza Kemboly (2017, pp. 173-180).

${ }^{17} \mathrm{O}$ "The-one-of-Heseret" [El de Heseret] o "The-one-who-loves-knowledge" [El que ama el conocimiento], como se le llama en el "Libro de Thot", en el papiro Berlin P 15531 as B02, entre otros (Jasnow y Zauzich, 2014, pp. 26, 30, 113). 
después, en particular en la era ramésida, en la esfera jurídica (Menu, 1982, pp. 285, 288).

Es importante entender que la maât no es una norma ya elaborada, fija, estática. En cambio, es "suprasensible", subjetiva, debe hacerse cotidianamente por parte del faraón "en su país y para su país, pero con la colaboración de este país" (Théodoridès, 1966, p. 57). Por ello es que la justicia, como dice el texto de Hatnub citado por Anthes (apud Théodoridès, 1995, p. 18), debía ejercerse para que cada uno obtuviese su derecho, su maât:

Yo siempre he juzgado un asunto de conformidad con su 'maât' (su justicia) no según la 'maât' del Rey, o de tal o cual dios, sino según la de la causa en cuestión, lo que significa: de conformidad con los intereses de las partes presentes, porque se entiende que siempre uno se esfuerza por hacer salir del tribunal a las dos partes satisfechas (por las decisiones que se tomaron).

Y es por ello que cada sector social tiene el derecho de aplicar la maât en su espacio cotidiano. El mejor ejemplo es el del knbt de Deir al-Medina (Théodoridès, 1969, pp. 103-188). ${ }^{18}$

Pero, ¿cómo entender a la diosa como tal, y, sobre todo, su femineidad, en la que creo que radica también su importancia?

\section{Maât, hija del dios supremo}

Como tal, Menu (1995, p. 283) clarifica la significación de la diosa:

Maât, divinidad hija del demiurgo Râ, encarna la ciencia del bien y del mal que Thot domina, del cual es el Escriba y el Contable; Maât reviste tan sólo aspectos positivos: fecundidad, fertilidad, prosperidad, victoria, orden, justicia, equidad. Ella cristaliza una dinámica de triunfo

${ }^{18}$ Los estudios clásicos de este autor demuestran con claridad la aplicación de la maât en la vida cotidiana del egipcio común. Vid. los diversos artículos de Théodoridès (1995). 
cuyo agente es la realeza: al practicar esta virtud múltiple y al ofrendar a las divinidades, el rey garantiza a su país el reino de Maât, es decir, la victoria del orden sobre el caos, de la paz sobre la guerra, de la prosperidad sobre la miseria, de la justicia sobre la iniquidad.

Por su parte, C. Cannuyer (2010, pp. 15-16) ${ }^{19}$ considera que Maât, como hija de Râ, coexiste con él y participa sustancialmente en la creación del universo, al grado de que los mismos Râ y Amón aparecen como dependientes de ella; es sobre la diosa que se funda la legitimidad del poder faraónico. La diosa es garante de toda justicia y solidaridad derivadas de ella. Es fuente de inmortalidad para aquellos que practicaron cotidianamente, que vivieron de acuerdo con la maât.

Lo anterior tiene, dice Derchain, una explicación mítica: que el creador creó el orden del mundo y el universo mismo gracias a la diosa (Derchain, 1965, p. 14). Los Textos de las pirámides resaltan su importancia. En efecto, el parágrafo $1582^{\mathrm{a}}$

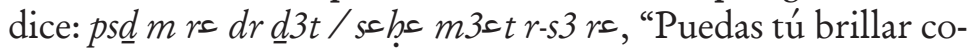
mo Râ reprimiendo el mal, y deja a Maât detrás de Râ" (Lichtheim, 1992, p. 16). Por ello es común observar a Maât como una de las divinidades protectoras de su padre celeste en su barca solar. Así se le ve en la tumba de Ramsés VI: dos diosas Maât conduciendo la barca del Sol en una procesión de siete divinidades y otros acompañantes de su progenitor divino. ${ }^{20}$

Para Gitta Warnemünde (2012, pp. 8-9), ${ }^{21}$ el origen de la diosa se recuerda en el parágrafo 80 de los Textos de los sarcófagos (Coffin Texts), donde Maât es mencionada en diversas secciones. En efecto, el documento dice:

Así dijo Atum: Tefênet es mi viviente hija, y ella estará con su hermano Shu; 'Viviente' es su nombre, 'Rectitud' es su nombre. Yo vivo con mis dos hijos (CT II, 32) [...] Yo me tiendo y vivo con mi hija Maât;

${ }^{19}$ La autora encuentra paralelismos claros entre el concepto de la mất y el ideal bíblico de la hokmât, la Sabiduría de Dios.

${ }^{20}$ Escena de la pared izquierda de la rampa al corredor F (Piankoff, 1954, pp. 232-235).

${ }^{21} \mathrm{La}$ autora señala en particular los Coffin Texts II 34g-35h. 
una dentro de mí y otra detrás de mí. Yo me levanto gracias a ellas, sus brazos me rodean (CTII, 32-33; traducción de Faulkner, 1978, pp. 83-84).

Este punto es básico, pues muestra el papel protector de Maât para con el dios creador, del cual es su ojo (Teeter, 2001, p. 319). Como cualquier madre protege a su hijo con sus brazos, Maât lo hace con su padre y esposo con sus miembros alados. El conjuro continúa:

Nu dijo a Atum: Besa a tu hija Maât, ponla en tu nariz, que tu corazón pueda vivir, porque ella no estará lejos de ti; Maât es tu hija y tu hijo es Shu, cuyo nombre vive. Come de tu hija Maât; es tu hijo Shu quien te elevará (CT II, 35).

En efecto, es sabido que Maât se relaciona con el alimento cotidiano del dios Râ. La diosa debe convertirse en la forma solar de la ofrenda alimentaria, ya que tiene por función básica nutrir y renovar al dios Sol (Shirun-Grumach, 1985, p. 173). Los Textos de los sarcófagos (III, $6^{\mathrm{a}}-7^{\mathrm{a}}$ ) la presentan como indispensable para el bienestar del mist, el hígado de Râ: "El que ofrece Maât a Râ cada día con el fin de que el hígado de Râ prospere gracias a Mât" (apud Meeks, 1995, p. 146). ${ }^{22}$

La idea implícita es que Maât tiene que ver con la ingesta de los alimentos, con la nutrición de hombres y dioses. Los textos tardíos la ligan con la garganta o el esófago (Meeks, 1995, p. 146). Pero en el hígado reside también, para los egipcios, un poder particular que varía de los hombres a los dioses, pero que tiene que ver con el carácter mismo del hombre, su $q d w$, que puede ser percibido a través de este órgano. Por ello el carácter, la naturaleza misma del demiurgo solar, es la

${ }^{22}$ Es el encantamiento 165, que Faulkner (1978, p. 143) traduce: "Spell from eating bread from upon the offering-tables of Râ, giving oblations in Ōn. O you who are content with what you have done - four times- and who send M3st to Re daily, the liver of $\mathrm{R} \varepsilon$ is flourishing daily because of $M 3 s t$, and he partakes of the meal of the Great Goddess, I am hale from every ill which has gone forth from the mouth of any god, any spirit or any dead person in this year and in this happy day of the $\underline{t} n n t$-sanctuary $[\ldots] \mathrm{I}$ am the Sole One [...] I have set before myself that I may eat hat is before me. I am this one who issued from the egg of the great god". 
de ser Maât, con lo que también se mantienen la naturaleza y el buen orden del mundo a través de tal ofrenda alimenticia simbolizada por la diosa (Meeks, 1995, pp. 154-155). Ella es el sustento básico de las divinidades egipcias (Teeter, 1997, p. 82).

\section{Maât, la diosa}

En el panteón egipcio, a los grandes dioses como Râ, Ptah, Amón, Osiris, Isis, Horus, entre otros, se les considera fundamentales. Empero, es de la hermosa diosa Maât de quien dependen el equilibrio cósmico y el orden del universo (Helck, 1980, cols. 1110-1111). El significado mismo de su nombre, "lo que debe ser", ${ }^{23}$ habla de su importancia fundamental en la cosmovisión egipcia. ${ }^{24} \mathrm{De}$ ahí que se le llame "Dama del Cielo", "Señora de las Dos Tierras", "ojo de Râ que no tiene igual", "Reina de los dioses y de las diosas" (Michailidis, 1953-1954, p. 444). Menu (1993, p. 48) insiste en el carácter dual de la diosa: es terrestre y cósmica, humana y divina, individual y universal; real e ideal, relativa y absoluta; representa al rey pero también a la divinidad; simboliza la tierra ( $t 3)$ pero también el cielo $(p t)$; lo masculino y lo femenino; la Tierra y el Sol unidos por Horus, Rey y Creador.

El numen es también la estrella Sirio, por lo que se relaciona con el inicio del año en verano, cuando aparece al alba. Entonces es considerada $n b t$ tp-rnpt st $(t)$ hepy $r$ tr.f, "la Señora del inicio del año, quien derrama la inundación al momento adecuado". Con ello se subraya su carácter benéfico, aso-

${ }^{23}$ En el que es tal vez el primer estudio monográfico sobre Maât, Stern (1878a, pp. 78-82 y 86-88) analiza el significado del nombre de la diosa y presenta sus diversas equivalencias en las lenguas indoeuropeas: verus, justus, Treue, Recht, true, truth, o el persa Durust. Pero también tüchtig, "eficiente". La investigación posterior comprueba plenamente tales interpretaciones, como se ve en el artículo básico sobre este tema de Helck (1980).

${ }^{24}$ Sobre la filosofía egipcia en torno al caos, lo contrario del orden establecido por la diosa Maât, cfr. Hornung, 1956, pp. 28-32. 
ciado a la fertilidad agrícola y la renovación de la naturaleza (Labrique, 2015, p. 238).

Como esposa de Thot, quien es "Toro de Maât" (Menu, 2005, p. 29), es responsable, junto con él, del juicio del muerto, por lo que puede considerársele como "Señora de Occidente". Junto con Hathor, son las "Señoras de las Tumbas" de la necrópolis tebana (Höber-Kamel, 2012, p. 5). Pero también Thot, gracias a sus poderes mágicos y a su sabiduría, contribuye a delimitar, junto con los demás dioses, el territorio del Doble País [wp t3wy], que entonces entregan a la diosa Maât, esposa de Thot. A Thot se le denomina "el buen sosegador, aquel que delimita el Doble País en el día de presentar la misión del padre a su hijo" (P. Liebig de Giessen apud Koemoth, 1995, p. 19). Con ello, Maât extenderá su protección al faraón y a su país, Egipto. Ahí radica la gran importancia de la ceremonia de ofrenda de la estatua de la diosa, bien conocida desde el Imperio Nuevo (a mediados de la dinastía XVIII, bajo Thoutmosis III), ${ }^{25}$ o a partir del Primer Periodo Intermedio, como quiere Karenga (1994, p. 571), y que implicaba la entrega de la estatuilla de Maât, como dice Moret (1940, p. 6), "al creador de esta VerdadJusticia”.

Para Derchain (1965, p. 14), "la ofrenda regresa a su creador [...] La ofrenda permite así la continuidad de la creación y asegura, entonces, la conservación del universo". Idea similar defiende Labrique (2015, pp. 239-240, 252-253). Por ello, las ofrendas relacionadas con la diosa implican una vivencia espiritual, simbólica, que trae aparejado haber practicado la verdad y la justicia sobre la tierra, según la doctrina divina (Moret, 1940, p. 7).

Por lo demás, la diosa tiene relación con otras divinidades primordiales del panteón, como šre, “estar vacío”, es decir el dios Shu, del que sería "hermana”. Menu (1993, p. 45) explica que en la Tríada primordial, donde el Uno llega a ser Tres con

${ }^{25}$ A decir de Menu (2005, p. 46) y Teeter (1997, pp. 7, 81). Esta última expresa: "Aunque la presentación de Maât es atestiguada por referencias textuales ya en el Reino Medio, no ocurre como un dispositivo iconográfico hasta el reinado de Thutmose III”. 
absoluta consustancialidad entre los miembros del grupo, Shu es el aire y el $\hat{a} n h$, la energía vital, o sea, un principio masculino; Tefnut, su hermana, es la humedad y la maât, el orden fértil y el principio femenino por excelencia. En ella residen y de ella derivan Tefen y Tefenet, lo masculino y lo femenino, reflejo de la androginia primordial del propio Atum.

Así surge Maâty, la Doble Maât, diosas colocadas en las dos extremidades de la balanza, con lo que presidirán el Gran Juicio del muerto. Una encarna la justicia particular, terrestre, testimonio de los actos del muerto a lo largo de su vida, por ello se le ve cerca del muerto, protegiéndolo con su brazo. La otra Maât lo hace entrar en la Sala del Tribunal y le indica el camino hacia el trono de Osiris, el juez supremo. Por lo tanto, la segunda diosa simboliza la justicia general, celeste, universal. "De un lado la solemnidad de todos los recursos de la teología y de la propaganda real; del otro, laicidad y pragmatismo" (Menu, 2005, pp. 91, 101).

Por ello, Maât es adorada en las dos riberas del Nilo. En la derecha, su santuario está en el gran espacio sagrado de Karnak, donde se le acepta sobre todo como la hija del dios creador, Râ, "que se une a Amón", por lo que se reconoce su carácter cósmico (Menu, 1993, p. 46). Pero tiene también un templo en la ribera izquierda, donde se le considera "Señora de Justicia" de Occidente, "para satisfacer la justicia" en el mundo de los hombres. ${ }^{26}$ Con ello aparece como garante del equilibrio terrestre y humano, en el que el visir, el $\underline{t} 3 t y$, aplica la $H p$ (Nims, 1948, pp. 243-260)27 del faraón en beneficio de Egipto. Ése es el

${ }^{26}$ Teeter (2001, p. 321) dice que los títulos de la Maât de Occidente en la era ramésida eran "Mistress of the West" [Señora de Occidente], "Mistress of the West who resides in the necropolis" [Señora de Occidente que reside en la necrópolis] y "Mistress of the Necropolis" [Señora de la necrópolis]. Esta última es st M3ءt, "el lugar de la verdad" y "el lugar para aquellos que han hecho maât" bajo la sombra del "gran pico de Occidente en éste su nombre de Maât".

${ }^{27}$ Sobre las características básicas del derecho egipcio, "les règlements", $c f r$. Me$\mathrm{nu}, 1993$, pp. 62-64, 74. La autora lo define como "El precedente que establece una jurisprudencia cuando la costumbre es silenciosa o insuficiente en un determinado punto de litigio". Son simplemente las hpw, las leyes, según Théodoridès (1967, p. 131). 
principio básico del accionar del faraón: "El rey hace venir la maât al país y rechaza la isfet” (Menu, 2005, p. 10). Aún en la época de Amarna, Ajenatón reconoce la importancia de la diosa frente al Atón: “Allí vive el Dios bueno, que goza de la maât, Señor de los Cielos, Señor de la Tierra, Atón viviente, grande, que ilumina las dos tierras; mi padre que vive..." (apud Anthes, 1952, pp. 11, 27-31)..$^{28}$

En su carácter de "Señora de Justicia", Horus reconoce su papel en el juicio de la Enéada que le confirió el trono de Egipto. En los Textos de las pirámides, parágrafo 260, se lee:

Oh, Geb, toro de Nut, yo soy Horus, heredero de mi padre. Yo soy aquel que se ha ido y ha regresado; el cuarto de estos cuatro dioses, quien trae el agua [de la inundación], administra la vegetación que nace, y celebra lo que hace el brazo de sus padres; aquel que quiere ser justificado en lo que ha hecho. Por el juicio entre el huérfano y los huérfanos que ha sido hecho para mí, el Doble Maât ordenó que el trono de Geb me sirva, que yo me levante a mí mismo para hacer lo que quiera, que mis miembros que estuvieron en secreto se unan, que yo los una en $\mathrm{Nu}$ y que yo ponga fin a la disputa en Heliópolis. Ahora que yo he surgido hoy en la forma verdadera de un $3 b$ [espíritu bendecido] viviente, yo interrumpiré la lucha y refrenaré el escándalo. Yo he surgido para Maât para que yo pudiese obtenerla, y ella está conmigo (Allen, 2015, p. 50. Cfr. traducción de Faulkner, 1969, p. 69).

\section{La diosa Maât en algunos textos literarios: reflejo de las vicisitudes de la sociedad egipcia}

Desde luego, la presencia de Maât en los textos literarios egipcios es constante. A. Volten (1963, pp. 73-101) ha estudiado tal aspecto en Ptahbotep, Amenemope, Any, el papiro Insinger

${ }^{28} \mathrm{El}$ estudio de Anthes presenta diversos ejemplos de la titulatura relativa a Maât en la época de Amarna. Para él, Maât es la fuerza integradora de la reforma de Ajenatón. El respeto de Ajenatón por la diosa es notable. Los textos que estudia Žabkar (1954, pp. 89-90) presentan una imagen parecida: "El gobernante de Maât nace como Atón, y permanece su forma (es decir, la de Atón) en la eternidad de la vida y hace millones de jubileos, que el Atón vivo ha decretado para él [...] Le das a luz [...] como tu imagen, como Atón, gobernante de Mait, que surgió de la eternidad...”. 
Merikare. Fecht (1958) lo analiza para el caso también de Ptabhotep. De hecho, el Cuento del campesino elocuente fue considerado por Assmann (1990, pp. 58-91) como un verdadero tratado sobre el M3єt (cfr. opinión de Parkinson, 1996, p. 142). Para A. Loprieno (1991-1992, p. 12), los aspectos fundamentales de la ideología política estatal que definen a la maât son: la fidelidad al soberano, a la estructura jerárquica de la sociedad y a la ideología nilocéntrica, temas que recoge la "littérature loyaliste" ["literatura de lealtad"] en textos como las Máximas de Hardjedef, de Kagemni o de Ptahhotep.

Me interesa resaltar el caso del texto "histórico-literario" de las Admoniciones de un sabio egipcio, es decir, el papiro hierático Leiden 344 rectum,$^{29}$ también conocido como El lamento de Ipuwer (Quirke, 2004, pp. 140-150, otra relativamente reciente traducción) o, de acuerdo con una de las más recientes traducciones del texto por R. Enmarch (cfr. 2005 y 2009), El diálogo de Ipuwer y el Señor de Todo. ${ }^{30}$

En las Admoniciones, Maât aparece en tres parágrafos. En 3,12 el texto dice:

Mitw kmw sḥ iw pr $\underline{h} \underline{d} r m \underline{b} m t n$ b3kw.f

¿Para qué sirve una Casa del Tesoro ante la ausencia de rentas?

nfr is ib n nsw iw. n.f m3te br is

Bueno será el corazón del rey cuando a él venga la verdad.

Y en el 3,13 se lee:

[d]d] bुst nbt mw n pw w3 $\mathrm{d}$ n pw ptr irt.n r.s w3w r $3 q w$

Toda tierra extranjera dice: 'Ésta es nuestra agua, ésta nuestra felicidad y fortuna. ¿Qué hacemos ante ello? ¡Caemos en ruina!’

${ }^{29}$ Utilizo en mis traducciones la transliteración al jeroglífico de Gardiner (1909).

${ }^{30}$ Este título fue propuesto por Parkinson hace años. De hecho, escribió "Ipuur". Cfr. The Tale of Sinube... (1997, pp. 166-199). Cambió el título que había utilizado en otra publicación previa (Parkinson, 1991, pp. 60-61), el "Lament of Ipuur”. 
Lo anterior, la desesperanza, es resultado de un concepto clave que resume la conspiración contra Maât: la "lucha civil". En 3,10-3,11 se lee:

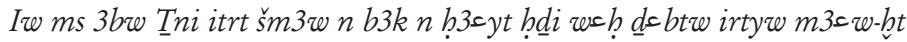
$n w t-h t s t 3 w-h t ~ k 3 t-h m m w t$

He aquí, Elefantina, Thinis, son dominios del Alto Egipto, pero no pagan impuestos a causa de la lucha civil. Se carece de algarrobo, de carbón, de mineral azul, de diversos tipos de madera, falta el trabajo de los artesanos...

Y todo este desquiciamiento económico y social, en el contexto del documento histórico-literario de las Admoniciones, es producto de la acción de los grandes enemigos de la diosa Maât en su vertiente social: "los hombres y las mujeres que no tienen planes" y que osan rebelarse contra ella. En efecto, en 7,2-7,3 se lee:

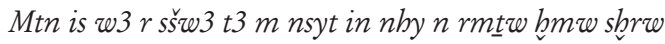

Miren, la realeza de la tierra se empobrece a causa de unos pocos hombres y mujeres ignorantes de planes.

¿Dónde reside su principal falta? En 7,3-7,4 se lee:

Mtn is w3 r sbiw ḥr is rt nb̆t $R=$ shrt t3rey

Miren, [esos hombres y mujeres] osan rebelarse en contra del Uraeus. Sólo Râ es fuerte y victorioso, es quien hace la paz (o sea, suprime la rebelión y a los rebeldes) en las Dos Tierras.

Es lo mismo que se observa en los parágrafos 12,12-12,13:

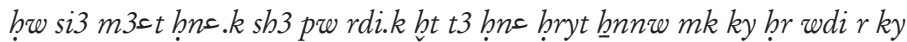
sny.twe $r$ wdt.n.k

La Voz, la Comprensión y la Verdad están contigo. ${ }^{31}$ [Pero] esta confusión que tú causas a través de la tierra [favorece] el estruendo de los

${ }^{31}$ Sokolova e Ilin-Tomich (2013, p. 269) traducen: "When he does it as one who would attack us, who will treat it [when] you disdain to save? Utterance, Perception 
rebeldes. He aquí, uno se pone contra otro. Uno transgrede ${ }^{32}$ las órdenes que tú [has dado].

Finalmente, el parágrafo 5,3-5,4 completa e insiste en las ideas anteriores:

Iw ms [m3st] ht t3 $m$ rn st prey isft pw iri.sn ḥr grg ḥr.st

De hecho, la Verdad está a través de la tierra en su nombre, pero el mal [que los hombres] hacen es la mentira que está con ellos.

Llama la atención que el gran enemigo de la diosa en su carácter social es la rebelión de los hombres. Cualquier hombre es un pecador en potencia, un hacedor de maldad, un codicioso. La naturaleza del rbyt lo inclina al desorden, al rompimiento del $M 3 \_t$. Precisamente, uno de los deberes del poderoso era "eliminar el conflicto del rbyt" ${ }^{33}$ de estos hombres violentos, como lo indica el papiro Prisse $(5,4)$, que son los rebeldes contra el monarca y que debían sufrir las consecuencias de sus actos, como interpreta Pavlova (1999, pp. 103-104).

Los rbyt sntt, el pueblo común, son aquellos a los que, por su actitud, se les considera orgánicamente el "pueblo rebelde" a su señor, hostil al faraón, y que nunca alcanzarán el Occidente y serán enviados al desierto para ser devorados por las aves, como indica el papiro Chester Beatty III $(11,8)$. Son equiparados con el dios Seth, viciosos hacedores del mal (Pavlova, 1999, pp. 91, 100, 102). Según esta autora, para los egipcios la esencia de la humanidad era su naturaleza corrupta, por ser proclives a la revuelta. Creo que el documento histórico-literario de las Admoniciones puede comprobarlo, y también, desde luego, el parágrafo 1130 de los Textos de los sarcófagos. ${ }^{34}$

and Truth [Hu, Sia y Maat] are taken away from you". El sentido de otros egiptólogos es "are with you", que prefiero.

${ }^{32}$ Es preferible traducir sny.tw en su sentido de "transgredir", más adecuado para el contexto del que habla el párrafo.

${ }^{33}$ En las Admoniciones aparecen también los rbyt, en 9,6 y 15,2.

${ }^{34}$ Se habla aquí de lo que considero una "condena ideológica" a los rebeldes, lo que he analizado en Castañeda, 2003, cap. 3 y passim. 
Como se ve, estos documentos parecen derivar directamente de la difícil época que sufrió el Egipto antiguo a finales del Reino Antiguo o en el Primer Periodo Intermedio de su historia, etapa que quedó reflejada en el documento histórico de Ipuwer, y que es un punto más que refleja la interpretación de su historicidad. ${ }^{35}$ Forma parte de lo que Allen (2009, p. 272) considera "una nueva respuesta a situaciones del momento, un método innovador para externalizar y lidiar con problemas percibidos"; ${ }^{36}$ en este caso, el rompimiento del orden social, la pérdida del $M 3 \approx t$, tan frágil y poderosa como la misma Hija de Râ. Y este acto "vil" contra el equilibrio del universo lo realizan egipcios, los "rebeldes contra el Uraeus", como el verbo sbiw en el parágrafo 7.3 muestra con claridad.

Muhlestein (2015, p. 1483) observa que ese verbo se emplea siempre en contextos en que los rebeldes son egipcios. Si fuesen extranjeros, se emplearía bšt. ${ }^{37}$

James P. Allen (2009, pp. 271-272) señala que textos como Khakheperre-sonb y Neferti, comparables a Ipuwer por su contenido en torno al "estado de las cosas" en el País de las Dos Tierras, reflejan las nuevas preocupaciones sociales y políticas que emergen en el Reino Medio. Manifiestan la inquietud por situaciones contrarias a la maât encarnada por la hija de Râ.

${ }^{35}$ Temática que he discutido en otros trabajos. Vid. Castañeda, 2018.

${ }^{36} \mathrm{El}$ autor aclara que, como resultado de los cambios en el proceso de transición del Primer Periodo Intermedio al Reino Medio, la preocupación por el mantenimiento del $M 3 \_t$ se amplía de las instituciones estatales a los individuos mismos, la gran innovación del periodo.

${ }^{37}$ Es otro ejemplo de las tendencias "sociológicas" de Ipuwer, al que algunos autores consideran autor de un texto tan sólo "literario", no histórico-literario, como me parece a mí, es decir que Ipuwer da cuenta de un acontecimiento que efectivamente ocurrió en el País del Nilo, en un texto literario pero histórico en cuanto al proceso de rebelión popular que narra poéticamente, a la manera que explica Kitchen (1999, p. XIII): "La poesía es el uso artístico -y las variaciones en el uso- del lenguaje en formatos no mundanos, para crear efectos especiales en las mentes de los lectores u oyentes [...] Puede ser creada a voluntad de un escritor para su propio beneficio con el fin de satisfacer nada más que sus impulsos creativos internos, o de otra manera servir a un objetivo específico: por ejemplo, [...] expresar sentimientos sobre un tema determinado”, entre otros propósitos. El objetivo poético del poeta-sociólogo Ipuwer sería, por tanto, embellecer literariamente una realidad histórica concreta que habría conocido. 
Constituyen verdaderos "diálogos internos", dirigidos primeramente al "propio corazón" de sus autores, pero también se "verbalizan", y entonces se dirigen a un público más amplio, dentro del cual destacan los encargados de la preservación social y política de la maât, es decir, el faraón y los miembros de su gobierno, y las divinidades mismas, como el Señor de Todo. $¿$ No es la principal responsabilidad de tal numen mantener el orden del que dependen los hombres, la naturaleza, las divinidades mismas, la maât universal?

Por ello, el Cuento del campesino elocuente retoma el tópico del $M 3 \_t$ desde el punto de vista de la búsqueda de la "justicia social" de la época. ¿Como reflejo de la "Revolución social" de que habla Ipuwer?: "Habla con justicia, haz la justicia, porque ella es poderosa; es grande, perdura, es valiosa, meritoria, es fiable, te lleva a ser reverenciado" (traducción M. Lichtheim, 1975-1980, vol. I, p. 181).

\section{Maât en la vida cotidiana de la mujer egipcia}

Lo anterior conduce al punto central de este trabajo: la importancia de la diosa Maât en la vida diaria del egipcio antiguo y, por ende, en la vida de ultratumba, prolongación de la primera, y en relación con las mujeres egipcias en particular.

Ya L. Manniche (1994-1995, p. 59) había señalado que la diosa Maât era fundamental en el pensamiento egipcio por mantener el orden cósmico y evitar su destrucción. Empero, dice que: "Si bien es adorada en la forma de una mujer, su sexo no tiene ningún significado en particular". Lo que es más: "Ella solamente podía realizar su tarea cuando era asistida por el rey de las Dos Tierras. Maât era una suerte de catalizador que facilitaba el equilibrio sin tomar una parte activa en hacerlo". Y su importancia es tal que el mismo Ajenatón aparece ofrendando la estatuilla de la diosa al Atón.

No estoy de acuerdo con lo anterior: el carácter "femenino" de Maât debe ser resaltado, porque de ahí deriva, en 
última instancia, la trascendencia de la diosa y su papel como conservadora del orden universal.

Curiosamente, entre los sectores populares, el culto a Maât no es fácilmente rastreable, al menos en los testimonios que recoge B. Gunn (1916, pp. 81-94). De hecho, el pueblo no abandonó nunca sus cultos tradicionales: los antiguos dioses (Horus, Hathor, Osiris) fueron siempre adorados por los grupos populares a lo largo de la historia egipcia (cfr. Woolley, 1922, p. 59, y Peet, Gunn, Guy, Newton y Wooley, 1923, p. 66). Pero lo mismo podría pensarse de la diosa de la Justicia, que preside el Lugar de la Verdad, un espacio especial en la necrópolis tebana, como considera Gunn (1916, p. 84).

Además de señalar que la documentación estudiada por este autor es escasa, M. Lichtheim (1988) recoge textos de diversas etapas de la historia egipcia que reflejan la "piedad personal" respecto del mantenimiento de la mất, que no se retoman aquí. ${ }^{38}$

Este punto se liga, por tanto, con las obligaciones de la vida cotidiana que mujeres y hombres en Egipto debían cumplir cotidianamente, además de los grandes rituales celebratorios de los dioses y sus representantes en la tierra. En cambio, como explica Derchain (1965, pp. 13-14):

Maât era naturalmente todavía otra cosa. En su actividad cotidiana, los hombres se respaldaban, se ajustaban a la maât, decían maât, hacían maât, es decir, hablaban y procedían conforme al orden establecido [...] Mientras que todos los seres vivos eran considerados cada uno por

${ }^{38}$ Vid. también Lichtheim, 1992, p. 9 (Reino Antiguo: inscripción de Seshem Nefer, Šrm-nfr, de Giza, fines de la dinastía v) y p. 20 (Primer Periodo Intermedio: etapa en la que las inscripciones relativas a Maât son raras, tumba de Hetepi, Htpi). El nombre del personaje remite a otro concepto clave del pensamiento egipcio, y muy ligado también al de la maât: el de ḥtp, estudiado por Davies, 2010, pp. 35-36 (Reino Medio: tumba del oficial Remeny Ankh, Rmny-shh, dinastía XII), pp. $78-79$ (Imperio Nuevo: tumba del "gran artesano" Karo, KRI VII 410f, de la época de Ramsés II), y pp. $92-93$ (sacerdote de bajo rango en el culto al dios Ptah, Estela SIM.4030 estudiada por Vercoutter). Žabkar, 1954, pp. 94-95 (Época de Amarna: tumba del chambelán Tutu). Este autor traduce la inscripción a partir de la transcripción de Maj Sandman, 1938, pp. 71, 74, 75, 77. 
su integración en el orden, el esfuerzo de todos era representado en el templo bajo la forma de una ofrenda de la imagen del orden al dios que lo había establecido.

Pero más allá de todo lo dicho, ¿dónde reside la fortaleza de la diosa Maât? Creo que tiene que ver con su carácter femenino: el numen simboliza también a la mujer egipcia. Por ello fue considerada como la hermosa y grácil hija del dios creador. En su aparente fragilidad reside su fortaleza, como en el caso de las hermosas mujeres del valle del Nilo. ¿Quién hubiese podido resistirse a la belleza y el amor por la vida que ellas simbolizaban? Las hijas de aquella tierra que algunos extranjeros consideraban

El verdadero hogar de Afrodita, ya que todo lo bueno que existe y que tiene lugar en el mundo está en Egipto [...] el vino, todas las cosas buenas que uno puede desear. ¡Y las mujeres! Más en número que las estrellas que muestra el cielo. ¡Y cómo se ven! Como la diosa cuya belleza una vez fue juzgada por Paris, lo juro por Démeter (según el escritor de comedias Hèrôdas or Hérondas, en el siglo III a.n.e., apud Montserrat, 1996, pp. 167-168).

Creo que la figura de la diosa Maât debe resaltarse, precisamente, como muestra de la importancia de la mujer en el Egipto antiguo, y quizá también del carácter uterino de esta civilización. ${ }^{39} \mathrm{Si}$ bien la desigualdad de género existió en el

${ }^{39}$ Sobre la caracterización de la civilización egipcia como fálica o uterina hay diversos estudios. Tal vez uno de los análisis más completos respecto de la civilización egipcia fálica sea el de Hare, 1999. La importancia de este trabajo para el tema, en mi opinión, es similar a la del trabajo de Keuls (1993) para la caracterización de la Atenas clásica como "falocrática”. En contraste, Troy (1986, pp. 8-9, 16) analiza la importancia de la diferenciación de género en el Egipto antiguo y de la interacción de los opuestos, factor de mutua revitalización y transformación, y, entre otros tópicos de su importante estudio, resalta que, por ejemplo, "la dualidad de los modos masculino y femenino, definida en términos de modos fálico y uterino, es, en la cosmología heliopolitana, el punto focal para la secuencia de concepción y nacimiento". Por mi parte, estudié comparativamente ambas perspectivas en Castañeda, 2008, pp. 182-311, y Castañeda, 2010, por lo que remito a tales estudios para un desarrollo más amplio del tema. Concluyo que la civilización del antiguo Egipto fue uterina o, si se quiere, "ginecocrática", como menciona Cannuyer (2010, p. 7), con base en lo que, a mi 
País del Nilo, las mujeres tuvieron diversas funciones sociales y religiosas, además de importantes rasgos simbólicos. En el mismo acto de la creación del universo, que ha escandalizado a no pocos egiptólogos, la importancia del elemento femenino es manifiesta: los Textos de las pirámides mencionan que el dios Atum se masturba en la colina primordial en forma de pirámide que se levanta en medio del caos primordial y genera a la primera pareja de dioses, Shu y Tefnut. ${ }^{40}$ Pero "la mano que lo apacigua", finalmente, no es la suya, sino la de la diosa Hathor, una de las varias divinidades que simbolizan el principio femenino, la mano que es adorada en los templos por su papel fundamental en el momento de la creación (Rossini y Schumann-Antelme, 1992, pp. 3-10).

Y también el dios Râ, el Sol, será diariamente protegido por el cuerpo de la diosa Nut, numen del cielo que se lo traga a través de su boca cada tarde, y lo ayuda a sobrevivir para atravesar el mundo de la oscuridad durante la noche y a renacer de su cuerpo en la mañana. Con esta acción, el principio del eterno Renacimiento del que depende el universo todo, se alcanza a través del cuerpo de la divinidad. ${ }^{41}$

juicio, parece una preponderancia del elemento femenino en diversos aspectos de la civilización egipcia, a pesar de que no pueda negarse el culto fálico en la religión ni la diferencia de género en favor del hombre. Ello tal vez permitiría inferir, con base en el análisis de aspectos relacionados con las esferas religiosa, política, social o jurídica, que esta civilización tuvo un carácter uterino. Asimismo, ciertos textos llevan a reflexionar favorablemente en torno al papel de las mujeres en la historia egipcia. En uno de estos documentos se menciona que el destino mismo del orbe dependía de ellas: "Es en la mujer en la que la buena y la mala fortuna descansan en este mundo" (Instrucción del papiro Insinger, siglo II a.n.e., en Lichtheim, 1975-1980, vol. III, p. 192, según la traducción de Manniche, 1987, p. 99). Lichtheim (1983, p. 162) prefiere traducir: "Es en la mujer que el buen demonio (špšyt) y el mal demonio (wr $3 t)$ están activos sobre la tierra". Opino que la primera traducción tiene un sentido más claro. Por su parte, Troy (1984, pp. 78-79) discute el doble carácter de la naturaleza femenina, "buena” y "mala", en un sentido similar al que se menciona.

${ }^{40}$ Referencia tomada de las pirámides de Merenre y Fiope o Pepi II (dinastía vI), en Pritchard, 1974, p. 3. Cfr. Allen, 2000, pp. 143-145, y Manniche, 1987, pp. 52-53.

${ }^{41}$ Es posible observar lo anterior en el techo astronómico de la tumba de Ramsés VI. Vid. Vernus, 1998, p. 123. 
Lo que es más, Maât aparece como la Buena Madre que protege y alimenta a su hijo al amamantarlo, igual que habría hecho la hija del Sol con su padre, Atum-Râ. Por ello es que el faraón tiene entre sus deberes básicos el de protegerla (Dereser, 2012, pp. 12-16). Al preservarla, protege su propia naturaleza divina y defiende el país de las Dos Tierras. Ahí radica el papel fundamental de la diosa para el egipcio común y corriente, y no sólo en su carácter funerario. ${ }^{42}$ Por eso a Râ, su padre, en una oración ritual ("Ritual de Amón” de Berlín) le dice:

Tú asciendes con Maât, tú vives de Maât [...] Tu hija Maât, tú rejuveneces a su vista, tú vives de Maât [...] Tu Hija Maât [...] tú vives del perfume de su rocío [...] A continuación [vienen] los dioses y las diosas que están contigo y llevan a Maât, ellos saben que tú vives de ella; tu ojo derecho es Maât, tu ojo izquierdo es Maât, ${ }^{43}$ tus carnes y tus miembros son Maât, los suspiros de tu vientre y de tu corazón [vienen] de Maât [...] eso que tú comes es Maât [...] los soplos por tu nariz son Maât [...] Las dos mitades de la tierra vienen a ti, llevando a Maât, para darte todo el orbe del disco solar [...] Maât se encuentra entre los dioses reunidos del ciclo $[\ldots .$.$] tú existes porque Maât existe.... { }^{44}$

La mención de la diosa Maât en uno de los textos más hermosos dedicados a las mujeres egipcias no es gratuito: es corolario definitivo de todo lo que he dicho. Además de por su

${ }^{42}$ Sobre el que Teeter (1997, pp. 86-89) insiste, sobre todo para el periodo ramésida. Debe recordarse que a través de la fórmula $m 3 \varepsilon$ brrw, que quiere decir "la aclamación que se le da a él es 'correcta”, se alcanzaba la salvación eterna. Esta expresión se originó en el culto al faraón y a Osiris (Anthes, 1954, pp. 50-51), para luego ser aplicada a todo egipcio que la mereciese. Stern (1878b, pp. 120-124) considera las diversas posibilidades de traducción de la expresión, relacionada también con el tema que nos ocupa. Destacan, entre otros, los sentidos: "Es triumphiert (deine Gerechtigkeit)", "waltend des Wortes", "mächtig des Wortes”, con lo cual se hace referencia al “poder mágico de las palabras”, ḥk3w, “magic, magic spells”, según Faulkner (1986, p. 179).

${ }^{43}$ La relación de Maât con el ojo de Râ recuerda también su liga con el "ojo de Horus”, el wd $3 t$, con lo cual se asegura el mantenimiento del equilibrio cósmico (Labrique, 2015, pp. 237-238).

${ }^{44}$ Traducción de A. Moret apud Michailidis, 1953-1954, p. 444. Cfr. Moret, 1902, pp. 140-144. Vid. los comentarios de Menu, 2005, pp. 53-54. 
belleza, su sabiduría y su fortaleza de carácter, la mujer egipcia, simbolizada por esta hermosa diosa, fue, por tanto,

Señora de gracia, dulce de amor, de sabio y placentero hablar, benéfica en el consejo de sus escritos, discurre todo en sus labios como pasa en las obras de la diosa Maât, ella es excelente, confiable, virtuosa, es grande y perfecta en los favores que le otorga a su comunidad, extiende su mano a todos, dice lo que es bueno y correcto, repite lo que es amoroso, hace el bien a cada uno, lo que saben sus labios no causa tristeza en el corazón de nadie, es grande su bondad y su amor para todos... ${ }^{45}$

\section{Conclusión}

El Egipto antiguo fue, por tanto, una civilización que, a pesar de las innegables diferencias de género que en ella existieron (Robins, 1996, pp. 190-191), le dio a una mujer el papel de representar el concepto cardinal de su concepción del mundo, de su cosmovisión (Cannuyer, 2010, p. 13). Esto constituye, desde mi perspectiva, un argumento más que permite, tal vez, considerar a la civilización egipcia más que fálica, uterina, lo que acentúa el papel de las mujeres en ella. Junto con su fragilidad y su belleza, Maât permite mantener el orden creado por los dioses al principio de los tiempos, divino y humano, puesto a veces en riesgo por "hombres [y mujeres] que no tienen planes" y que convocan a modificar el ordo social que de ella depende, con lo que provocan la isft, el caos, que sólo ella es capaz de conjurar.

$\mathrm{Y}$, curiosamente, para aquellos que se lanzaron a construir su propia historia durante la "Revolución social" a finales del Reino Antiguo o Primer Periodo Intermedio a través de la

${ }^{45}$ Mi traducción. Aquí, la de Gustave Lefebvre (1923, pp. 10-12, 101): “Souveraine de gràce, douce d'amour, à la parole profitable, agréable en (ses) discours, de conseil utile dans ses écrits; tout ce qui passe (sš) sur ses lèvres est à la ressemblance des travaux de Maât; femme parfaite, grande de faveurs dans sa ville, tendant la main à tous, disant ce qui est bien, répétant ce qu'on aime, faisant plaisir à chacun, sur les lèvres de qui rien de mal ne passe, grande d'amour près de chacun...”. 
búsqueda de la justicia social, y que fueron fundamentalmente mujeres, ${ }^{46}$ como acertadamente escribe C. Cannuyer (2010, p. 13), la diosa representa la "Verdad-Justicia", la solidaridad humana, la reciprocidad social, que funda la ética y el Estado de derecho.

¿Y no el dios creador, el padre de nuestra diosa, había prometido la maât, la justicia social, a los hombres, como se lee en los Textos de los sarcófagos 1130 (VII 461-465), ${ }^{47}$ verdadero legado del Egipto antiguo en la búsqueda de superar las profundas diferencias económico-sociales entre los hombres, en el pasado y más en nuestros días?:

$N b r \underline{d} r \underline{d} d$ bt.f

Sgrw nšni m skẹdy

Šnwt

d3 3 m ḥtp wḥm.inț spw nfrw

iri.n ni ib.i $m \underline{\text { bn} w}$ m mḥnyt

$n$ mrwt sgrt isft
Señor de todas las regiones, Él dice ante

los que silencian la tormenta, mientras navegan

los cortesanos, los acompañantes de Râ

¡Salve, en paz! Yo te repito los dones buenos

que mi corazón hizo por mí al interior de "la que está enrollada" (la serpiente Apophis)

para silenciar el mal, el conflicto [para restablecer el dominio de la diosa Maât].48

${ }^{46}$ Pues ellas fueron uno de los objetivos de la rebelión, como analicé en Castañeda, 2003, pp. 126-133, y Castañeda, 2008, pp. 341-380.

${ }^{47}$ Utilizo para esta traducción la transliteración al jeroglífico de Buck, 1961.

${ }^{48}$ Como se ve, la diosa está implícita en esta frase que interpreto entre corchetes. La isft, la contraparte de la maât, es lo que los griegos llamarán siglos después stásis, castellanizado "estasis", la discordia civil, cuyo control llevó a la creación del sistema democrático en Atenas. Quizá más que en la "Constitución de Atenas" de Aristóteles, sea en la "República de Atenas", de Pseudo-Jenofonte, donde es más clara esta idea. Vid. Pseudo-Jenofonte, "La república de los atenienses" (2010, pp. 95-119). Cfr. la opinión al 
Iw $\left[m s^{49}\right]$ iri.n.isp [4] nfrw $m$ hanw sbbt $3 b$ t

$I w[m s]$ iri.n.it $\underline{3} w[4] \mathrm{ssn} s \mathrm{nb} m$ b3r.f

spimpw

Iw [ms] iri.n.i pn 3gb wor shbm ḅwrw im.f mi wr

spimpw

Iw [ms] irin.i s nb mi snw.f

$N n$ wd iri.sn isft

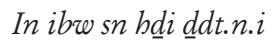

Iw $[\mathrm{ms}]$ iri.n.i tm nn ibw.sn r.smbुt Imnt

$n$ mrwt irit ḅtpt $n$ ntrwe sp3t

spimpw

Shpr.n.i ntrwe m fdt.i
En verdad, yo hice cuatro buenos dones desde el interior del Portal del Horizonte

En verdad, hice los cuatro alientos que respira todo hombre en su tiempo de vida

Por lo tanto, éste es el don.

En verdad, hice esta gran inundación, tanto para el poderoso como para el humilde.

Por lo tanto, éste es el don.

En verdad, hice a todo hombre como su hermano

No ordené que ellos (los hombres) hicieran el mal [sino que siguieran a la diosa Maât]

Por sus corazones desobedecieron lo que yo dije.

En verdad, yo hice que sus corazones no olvidaran nunca a Occidente

Para que se hagan ofrendas a los dioses de los nomos

Por lo tanto, éste es el don.

Hice que llegaran a ser los dioses de mi sudor

respecto de Ste. Croix (1988, p. 353) y de Pomeroy, Burstein, Dolan y Roberts (2001, pp. 377-379).

${ }^{49}$ Parece que esta combinación bien conocida del texto de las Admoniciones puede aplicarse, por su sentido, a este parágrafo, que no la presenta de hecho. $C f r$. las reflexiones de Gardiner (1909, pp. 21-23) sobre esta fórmula, que propongo utilizar aquí en mi traducción. 
[y] fue hecha por mí la humanidad de las lágrimas [de mi ojo] $]^{50}$

Creo que el último texto que traduje, en su contenido sobre la justicia social en el antiguo País de las Dos Tierras del Nilo, puede relacionarse con la opinión de Moret (1940, p. 14). Para este autor, la hermosa hija de Râ "ha hecho un regalo magnífico a la humanidad. Ella fue capaz de satisfacer, desde aquí en la tierra y con la esperanza de una realización más perfecta en el otro mundo, el grito irreprimible donde se afirma la dignidad del hombre y su superioridad sobre el animal: la Justicia”.

Por lo analizado y por esto último, es Maât la más poderosa diosa del panteón egipcio.

\section{Referencias}

Allen, J. P. (2000). Middle Egyptian. An introduction to the language and culture of hieroglyphs. Cambridge: Cambridge University Press.

Allen, J. P. (2009). Old and new in the Middle Kingdom. En D. P. Silverman, W. K. Simpson y J. Wegner (Eds.), Archaism and innovation: Studies in the culture of Middle Kingdom Egypt (pp. 263-275). New Haven, CT: Yale University-University of Pennsylvania Museum of Archaeology and Anthropology.

Allen, J. P. (Ed. y trad.) (2015). The ancient Egyptian pyramid texts. Atlanta, GA: Society of Biblical Literature. https://doi. org/10.2307/j.ctt14jxv34

Anthes, R. (1952). Die Maat des Echnaton von Amarna. Baltimore, $\mathrm{MD}$ : American Oriental Society.

ANTHEs, R. (1954). The original meaning of $m 3 \varepsilon$ brrw. Journal of Near Eastern Studies, 13(1), 21-51. https://doi.org/10.1086/371174

Assmann, J. (1990). Ma'at: Gerechtigkeit und Unsterblichkeit im Alten Ägypten. München: C. H. Beck.

${ }^{50}$ Recuérdese que la hija de Râ es copartícipe sustancial de la creación del universo, como ya se dijo. Así, interviene directamente en ese acto creador. 
BEREND, W. B. (1882). Principaux monuments du Musée égyptien de Florence. Première partie. Stèles, bas-reliefs et fresques. París: Imprimerie Nationale.

Betró, M. (2010). Ippolito Rosellini, l'Egitto, l'Egittologia. En Autor (Ed.), Ippolito Rosellini e gli inizi dell'Egittologia. Disegni e manoscritti originali della Spedizione Franco-Toscana in Egitto (1828-29) dalla Biblioteca Universitaria di Pisa (pp. 4-33). Pisa: Università di Pisa.

BiLolo, M. (1988). Le créateur et la création dans la pensée Memphite et Amarnienne: approche synoptique du "Document philosophique de Memphis" et du "Grand hymne théologique" d'Echnaton. Kinshasha: Publications Universitaires Africaines.

Bleeker, C. J. (1929). De Beteekenis van de Egyptische godin Ma-a-t (tesis de doctorado). Universidad de Leiden, Leiden.

BrunNer, H. (1958). Gerechtigkeit als Fundament des Thrones. Vetus Testamentum, 8(4), 426-428. https://doi.org/10.2307/1516152

Buck, A. de (Ed. y trad.). (1961). The Egyptian Coffin Texts. Vol. VII: Texts of spells 787-1185. Chicago, IL: The University of Chicago Press.

Cannuyer, C. (2010). La femme et le divin féminin dans l'Égypte ancienne. Regards dispersés et échappés inter-religieuses. Mélanges de Science Religieuse, 67(1), 5-26.

CASTAÑEDA ReYes, J. C. (2003). Sociedad antigua y respuesta popular. Movimientos sociales en Egipto antiguo. México: Universidad Autónoma Metropolitana-Plaza y Valdés.

CastañEda Reyes, J. C. (2008) Señoras y esclavas: el papel de la mujer en la historia social del Egipto antiguo. México. El Colegio de México.

Castañeda Reyes, J. C. (2010). El culto fálico y el culto uterino en el Egipto antiguo. En M. C. Valverde Valdés y M. Ruiz Velasco (Coords.), Teoría e historia de las religiones (vol. 2, pp. 145-180). México: Universidad Nacional Autónoma de México.

Castañeda Reyes, J. C. (2018). Concerning a new study on The Admonitions of an Egyptian Sage (or, The Dialogue of Ipuwer and the Lord of All). Göttinger Miszellen: Beiträge zur ägyptologischen Diskussion, (255), 41-53.

Davies, N. (1925). The tomb of two sculptors at Thebes. Nueva York, NY: Metropolitan Museum of Art.

Davies, V. (2010). The dynamics of hetep in ancient Egypt (tesis de doctorado). Universidad de Chicago, Chicago. 
DerchaIn, P. (1965). Le papyrus salt 825 (B.M. 10051), rituel pour la conservation de la vie en Égypte. Bruselas: Académie Royale de Belgique.

Dereser, C. (2012). Pharao als Verfechter der Maat. Kemet, 21(2), 12-16.

ENMARCH, R. O. (Ed.). (2005). The Dialogue of Ipuwer and the Lord of All. Oxford: Griffith Institute.

Enmarch, R. O. (2009). A world upturned. Commentary on and analysis of The Dialogue of Ipuwer and the Lord of All. Oxford: The British Academy. https://doi.org/10.5871/bacad/ 9780197264331.001.0001

Faulkner, R. O. (Ed. y trad.). (1969). The ancient Egyptian Pyramid Texts. Oxford: Clarendon Press.

FAulKneR, R. O. (Ed. y trad.). (1978). The ancient Egyptian Coffin Texts. Vol. I: Spells 1-354. Warminster: Aris \& Phillips.

Faulkner, R. O. (1986). A concise dictionary of Middle Egyptian. Oxford: Griffith Institute.

Fecht, G. (1958). Der Habgierige und die Maat in der Lebre des Ptahbotep (5. und 19. Maxime). Glückstadt: J. J. Augustin.

Gardiner, A. H. (1909). The admonitions of an Egyptian sage from a bieratic papyrus in Leiden, Pap. Leiden 344 Recto. Leipzig: J. C. Hinrichs.

GARDINER, A. (1925). The autobiography of Rekhmerê. Zeitschrift für Ägyptische Sprache und Altertumskunde, 60(1), 62-76. https:// doi.org/10.1524/zaes.1925.60.1.62

GuidotTi, M. C. (2010). Gli oggetti della spedizione di Rosellini nel Museo Egizio di Firenze. En M. Betró (Ed.), Ippolito Rosellini e gli inizi dell'Egittologia. Disegni e manoscritti originali della Spedizione Franco-Toscana in Egitto (1828-29) della Biblioteca Universitaria di Pisa (pp. 44-49). Pisa: Università di Pisa.

Gundlach, R. (1997). Die Legitimationen des ägyptischen Königs-Versuch einer Systematisierung. En R. Gundlach y Ch. Raedler (Eds.), Selbstverständnis und Realität. Akten des Symposiums zur ägyptischen Königsideologie in Mainz 15.-17.6-1995 (pp. 11-20). Wiesbaden: Harrassowitz.

GunN, B. (1916). The religion of the poor in ancient Egypt. Journal of Egyptian Archaeology, 3(1), 81-94. https://doi.org/10.1177/ 030751331600300124 
HARE, T. (1999). Remembering Osiris. Number, gender and the word in ancient Egyptian representational systems. Stanford, CA: Stanford University Press.

HeLcK, W. (1980). Maat. En W. Helck y E. Otto (Eds.), Lexikon der Ägyptologie (vol. III, cols. 1110-1119). Wiesbaden: Harrassowitz. Hermann, A. (1940). Die Stelen der thebanischen Felsgräber der 18. Dynastie. Glückstadt: J. J. Augustin.

Höber-KAmel, G. (2012). Maat-Lebensprinzip und göttliche Norm. Kemet, 21(2), 4-6.

Hornung, E. (1956). Chaotische Bereiche in der geordneten Welt. Zeitschrift für Ägyptische Sprache und Altertumskunde, 81(1-2), 28-32. https://doi.org/10.1524/zaes.1956.81.12.28

Hornung, E. (1989). Maat-Gerechtigkeit für alle? Zur altägyptischen Ethik. En R. Ristema (Ed.), Wegkreuzungen. Crossroads. La croisée des Chemins (pp. 385-427). Fránkfort: Eranos.

JASNOw, R. y Zauzich, K. Th. (2014). Conversations in the house of life. A new translation of the ancient Egyptian Book of Thoth. Wiesbaden: Harrassowitz.

Karenga, M. N. (1994). Maat. The moral ideal in ancient Egypt. A study in classical African ethics (tesis de doctorado). University of Southern California, Los Ángeles, CA.

Kemboly, M. (2017). Grappling with the notion of evil in ancient Egypt. En R. Jasnow y G. Widmer (Eds.), Illuminating Osiris. Egyptologicalstudies in honorofMark Smith (pp. 173-180). Atlanta, GA: Lockwood Press. https://doi.org/10.2307/j.ctvvnd2x.20

KeULs, E. C. (1993). The reign of the phallus. Sexual politics in ancient Athens. Nueva York, NY: Harper \& Row.

Kitchen, K. A. (1999). Poetry of ancient Egypt. Jonsered: Paul Åströms.

Коемотн, P. (1995). Délimiter le double pays en tant que territoire dévolu à Maât. Bulletin de la Société d’Égyptologie, (19), 13-23.

KüNH, T. (2012). Die Erscheinungsformen der Göttin Maat. Kemet, 21(2), 25-29.

Labrique, F. (2015). La tunique historiée de Saqqara: Maât-Alêtheia versus Isis-Perséphone (Planches I-II). En F. Colin, O. Huck y S. Vanséveren (Eds.), Interpretatio: traduire l'altérité culturelle dans les civilisations de l'Antiquité (pp. 231-264). París: Boccard. Lefebvre, G. (1923). Le tombeau de Petosiris. Vol. 1 : Description. El Cairo: Impr. de L'Institut français d'archéologie orientale. 
LichtheIm, M. (1975-1980). Ancient Egyptian literature. A book of readings (Vols. I y III). Berkeley, CA: University of California Press.

LichtheIM, M. (1983). Late Egyptian wisdom literature in the international context. A study of demotic instructions. Freiburg: Universitätsverlag. https://doi.org/10.5167/uzh-149699

LichtheIm, M. (1988). Ancient Egyptian autobiographies chiefly of the Middle Kingdom. A study and an anthology. Freiburg: Universitätsverlag. https://doi.org/10.5167/uzh-141274

LichTHEIM, M. (1992). Maat in Egyptian autobiographies and related studies. Freiburg: Universitätsverlag. https://doi.org/10.5167/ uzh-152368

LOPRIENO, A. (1991-1992). La letteratura lealista fra topos e mimesis. Egitto e Vicino Oriente, 14-15, 9-21.

Manniche, L. (1987). Sexual life in ancient Egypt. Londres: Kegan Paul International.

MANniche, L. (1994-1995). Divine reflections of female behavior. KMT. A Modern Journal of Ancient Egypt, 5(4), 52-59.

Meeks, D. (1995). Le foie, Maât et la nature humaine. En T. DuQuesne (Ed.), Hermes Aegyptiacus. Egyptological studies for $H$. B. Stricker (pp. 145-156). Oxford: DE Publications.

MENU, B. (1982). Recherches sur l'histoire juridique, économique et sociale de l'ancienne Égypte. Versalles: ed. del autor.

Menu, B. (1993). Maât et la justice des pharaons. Égyptes. Histoires \& Cultures, (1), 45-49.

Menu, B. (1995). Le tombeau de Pétosiris (2). Maât, Thot et le droit. Bulletin de l'Institute français d'archéologie orientale, (95), 281-295. Recuperado de https://www.ifao.egnet.net/bifao/095/13/

Menu, B. (2005). Maât, l'ordre juste du monde. París: Michalon. https://doi.org/10.3917/micha.menue.2005.01

Michailidis, G. (1953-1954). Contribution à l'étude de la grande déesse en Égypte. Bulletin de l'Institut d'Égypte, 36(1), 409-454.

MigliarinI, A. M. (1859). Indication succinte des monuments égyptiens du Musée de Florence, Florencia: Imprimerie Barbèra, Bianchi e Comp.

Montserrat, D. (1996). Sex and society in Graeco-Roman Egypt. Londres: Kegan Paul.

Moret, A. (1902). Le rituel de culte divine journaliere en Égypte. D'après les Papyrus de Berlin et les Textes du Temple de Séti Ier, à Abydos. París: Ernest Leroux. 
Moret, A. (1940). La doctrine de Maât. Revue d'Égyptologie, 4, 1-14. Muhlestein, K. (2015). Those who speak rebellion: Refining our understanding of the words used to describe 'rebellion'. En P. Kousoulis y N. Lazaridis (Eds.), Proceedings of the Tenth International Congress of Egyptologists. University of the Aegean, Rhodes 22-29 May 2008 (vol. 2, pp. 1473-1483). Lovaina: Peeters.

Nims, C. F. (1948). The term hp, 'law, right' in demotic. Journal of Near Eastern Studies, 7(4), 243260. https://doi.org/10.1086/370888

NeWBerry, P. E. (1900). The life of Rekhmara, vezîr of Upper Egypt under Thothmes III and Amenhetep II (circa B. C. 1471-1448). Westminster: Archibald Constable.

Parkinson, R. B. (1991). Voices from ancient Egypt. An anthology of Middle Kingdom writings. Londres: British Museum.

Parkinson, R. B. (1996). Individual and society in Middle Kingdom literature. En A. Loprieno (Ed.), Ancient Egyptian literature. History and forms (pp. 137-155). Leiden: E. J. Brill.

Pavlova, O. (1999). Rhyt in the Pyramid Texts: Theological idea or political reality. En J. Assmann y E. Blumenthal (Eds.), Literatur und Politik im pharaonischen und ptolemäischen Ägypten (pp. 91104). El Cairo: Institute français d'archéologie orientale.

Peet, E., Gunn, B., Guy, P. L. O., Newton, F. G. y Wolley, L. (1923). The city of Akhenaten. Part 1. Excavations of 1921 and 1922 at El-'Amarneh. Londres: Egypt Exploration Society.

Piankoff, F. A. (1954). Le tomb of Ramesses VI. Texts. Vol. I: Texts. Nueva York, NY: Pantheon Books.

PlutARCo. (1987). Sobre Isis y Osiris. En Autor, Obras morales y de costumbres (pp. 37-131). Madrid: Akal.

Pomeroy, S. B., Burstein, S. M., Donlan, W. y Roberts, J. T. (2001). La antigua Grecia. Historia politica, social y cultural. Barcelona: Crítica.

PRITCHARD, J. (Ed.). (1974). Ancient Near Eastern texts relating to the Old Testament. Princeton, NJ: Princeton University Press.

Pseudo-Jenofonte, La república de los atenienses (2010). En A. Ruiz Sola (Ed.). Las constituciones griegas (pp. 95-119). Madrid: Akal.

QuIRKE, S. (2004). Egyptian literature 1800 BC. Questions and readings. Londres: Golden House Publications.

RoBINs, G. (1996). Women in ancient Egypt. Londres: British Museum Press. 
Rossini, S. y Schumann-Antelme, R. (1992). Nétèr. Dieux d'Egypte. Lavaur: Trismegiste.

RoseluINI, I. (1830). Breve notizia degli oggetti di antichità egiziane riportati dalla Spedizione Letteraria Tosacana in Egitto e in Nubia eseguita negli anni 1828 e 1829. Ed esposti al pubblico nell'Accademia delle Arti e Mestieri in S. Caterina. Florencia: Stamperia Piatti.

SAndman, M. (Ed.). (1938). Texts from the time of Akhenaten. Bruselas: Fondation égyptologique Reine Élisabeth.

Serrano Delgado, J. M. (1998). Libro iI. El Egipto faraónico. En J. Sanmartín y J. M. Serrano, Historia antigua del Próximo Oriente. Mesopotamia y Egipto (pp. 177-372). Madrid: Akal.

Schiaparelli, E. (1887). Museo archeologico di Firenze. Antichitá egizii, ordinate e descritte da Ernesto Schiaparelli (Vol. 1). Roma: Tipografia della R. Accademia dei Lincei.

Shirun-Grumach, I. (1985). Remarks on the goddess Maat. En S. Israelit-Groll (Ed.), Pharaonic Egypt. The Bible and Christianity (pp. 173-201). Jerusalén: The Magnes Press.

Sokolova, M. e Ilin-Tomich, A. (2013). Twelve notes on Ipuwer. Chronique d'Égypte, 88(176), 261-272. https://doi.org/10.1484/J. CDE.1.103755

Ste. Croix, G. E. M. de (1988). La lucha de clases en el mundo griego antiguo. Barcelona: Crítica.

STERn, L. (1878a). Hieroglyphisch-koptisches. Zeitschrift für Ägyptische Sprache und Altertumskunde, (15-16)1, 72-78. https://doi. org/10.1524/zaes.1878.1516.jg.70

STERN, L. (1878b). Hieroglyphisch-koptisches. Zeitschrift für Ägyptische Sprache und Altertumskunde, (15-16)1, 113-124. https://doi. org/10.1524/zaes.1878.1516.jg.111

Teeter, E. (1985-1986). Multiple feathers and Maat. Bulletin of the Egyptological Seminar, (7), 43-52.

TeETER, E. (1997). The presentation of Maat. Ritual and legitimacy in Ancient Egypt. Chicago, IL: Oriental Institute of the University of Chicago.

TeEter, E. (2001). Maât. En D. B. Redford (Ed.), Oxford Encyclopedia of Ancient Egypt (vol. 2, pp. 319-320). Oxford: Oxford University Press.

The Tale of Sinube and other ancient Egyptian poems 1940-1640 BC. (Trad., introd. y notas R. B. Parkinson). (1997). Oxford: Clarendon Press. 
THÉODORIDÈs, A. (1966). Les Égyptiens anciens, 'citoyens' ou 'sujets de Pharaon'? Revue internationale des droits de l'antiquité, (20), 51-112.

ThéODORIDÈs, A. (1967). À propos de la loi dans l'Égypte pharaonique. Revue internationale des droits de l'antiquité, (14), 107-152.

THÉODORIDÈs, A. (1969). Les ouvriers-“magistrats”. En Égypte à l'époque ramesside (XIXe-Xxe dyn.; $13^{\mathrm{e}}-10^{\mathrm{e}}$ s. av. J.-C.). Revue internationale des droits de l'antiquité, (16), 103-188.

THÉODORIDÈs, A. (1995). La formation du droit dans l'Egypte pharaonique. En Autor, Vivre de Maât. Travaux sur le droit égyptien ancien (vol. 1, pp. 3-20). Bruselas: Société Belge d'Études Orientales.

Troy, L. (1984). Good and bad women. Maxim 18/284-288 of the Instructions of Ptah-hotep. Göttinger Miszellen. Beiträge zur ägyptologischen Diskussion, (80), 77-82.

Troy, L. (1986). Patterns of queenship in Ancient Egyptian myth and history. Upsala: Acta Universitatis Upsaliensis.

Vergote, J. (1961). Les prototypes égyptiens des mots coptes memèi 'verité, justice'. Bulletin de l'Institute française d'archéologie orientale, (61), 69-78. Recuperado de https://www.ifao.egnet. net/bifao/061/10/

Vernus, P. (1998). The gods of Ancient Egypt. Nueva York, NY: George Braziller.

Volten, A. (1963). Der Begriff der Maat in den ägyptischen Weisheitstexten. En Les sagesses du Proche-Orient ancien. Colloque de Strasbourg, 17-19 mai 1962 (pp. 73-101). París: Presses Universitaires de France.

WarnemÜNDE, G. (2012). Der Ursprung der Maat. Kemet, 21(2), 7-11. WeIgall, A. E. P. (1910). A guide to the antiquities of Upper Egypt. From Abydos to the Sudan frontier. Nueva York, NY: The MacMillan Company.

WestendoKf, W. (1971). Maat, die Führerin des Sonnenlichtes, in der Architektur. Zeitschrift für Ägyptische Sprache und Altertumskunde, 97(1), 143-146. https://doi.org/10.1524/zaes.1971.97. jg.143

Wiedemann, A. (1887). Maa, déesse de la vérité et son rôle dans le panthéon égyptien. Annales du Musée Guimet, 10, 559-573.

Woolley, L. (1922). Excavations at Tell El-Amarna. The Journal 
of Egyptian Archaeology, 8(1), 48-82. https://doi.org/10.1177/ 030751332200800107

ŽABKAR, L. V. (1954). The theocracy of Amarna and the doctrine of the Ba. Journal of Near Eastern Studies, 13(2), 87-101. https:// doi.org/10.1086/371191

José Carlos Castañeda Reyes es historiador y arqueólogo. Tiene estudios de maestría y doctorado en estudios de Asia y África, especialidad Medio Oriente, por El Colegio de México. Es profesor de tiempo completo en la Universidad Autónoma Metropolitana-Iztapalapa, en el Departamento de Filosofía. Investiga en torno a la historia antigua del Medio Oriente y la historia del islam clásico. Se interesa por la historia social del Egipto antiguo, concretamente los movimientos sociales en esta civilización. Estudia también las insurrecciones populares en el Egipto contemporáneo. Miembro del Sistema Nacional de Investigadores, nivel II, del Consejo Nacional de Ciencia y Tecnología, México.

https://orcid.org/0000-0003-4688-1483 mrwti@xanum.uam.mx 
